\title{
Agrobacterium rhizogenes-mediated transformation of Hypericum sinaicum L. for the development of hairy roots containing hypericin
}

\author{
Heba Desouky Khlifa ${ }^{1^{*}}$, Magdalena Klimek-Chodacka ${ }^{2}$, \\ Rafal Baranski², Michal Combik ${ }^{3}$, Hussein Sayed Taha ${ }^{\circledR *}$ \\ ${ }^{1}$ Plant Biotechnology Department, Genetic Engineering and Biotechnology Division, National \\ Research Centre (NRC), Dokki, Cairo, Egypt, ${ }^{2}$ Institute of Plant Biology and Biotechnology, Faculty \\ of Biotechnology and Horticulture, University of Agriculture in Krakow, Krakow, Poland, ${ }^{3}$ Vascular \\ Plants Department, W. Szafer Institute of Botany, Polish Academy of Sciences, Krakow, Poland
}

\begin{abstract}
Hypericum sinaicum L. is an endangered Egyptian medicinal plant of high importance due to the presence of naphthodianthrones (hypericins), which have photodynamic properties and pharmaceutical potential. We sought to assess $H$. sinaicum ability to develop hairy roots that could be cultured in contained conditions in vitro and used as a source for hypericin production. We used four $A$. rhizogenes strains differing in their plasmids and chromosomal backgrounds to inoculate excised $H$. sinaicum root, stem and leaf explants to induce hairy root development. Additionally, inoculum was applied to shoots held in Rockwool cubes supporting their stand after removal of the root system. All explant types were susceptible to A. rhizogenes although stem explants responded more frequently (over 90\%) than other explant types. The A4 and A4T A. rhizogenes strains were highly, and equally effective in hairy root induction on $66-72 \%$ of explants while the LBA1334 strain was the most effective in transformation of shoots. Sonication applied to explants during inoculation enhanced the frequency of hairy root development, the most effective was $60 \mathrm{~s}$ treatment doubling the percentage of explants with hairy roots. However, shoot transformation was the most effective approach as shoots developed hairy roots within 10 days after inoculation. Molecular analyses confirmed that the established hairy root cultures in vitro were indeed obtained due to a horizontal gene transfer from bacteria. These cultures grew fast and the hypericin content in hairy roots was about two fold higher than in H. sinaicum plants as determined by HPLC.
\end{abstract}

Keywords: In vitro culture. Medicinal plant. Naphthodianthrones. Plant genetic engineering.

\section{INTRODUCTION}

The genus Hypericum belonging to the Hypericeae family comprises approximately 450 species of trees, shrubs and herbs found in different temperate regions in the world (Mártonfiová et al., 2014). Some Hypericum species like H. perforatum (St. John's worth) have been recognized as valuable medicinal plants. In particular, Hypericum species have attracted attention due to the

*Correspondence: H. S. Taha, Plant Biotechnology Department, Genetic Engineering and Biotechnology Division, National Research Centre (NRC), P.O.12622 - Dokki, Cairo, Egypt. Tel/Fax: 00202333709 31. E-mail: Hussein.taha2@yahoo.com/heba2ali@yahoo.com content of unique bioactive constituents like hypericin and hyperforin classified to naphthodianthrones and phloroglucinols, respectively. These compounds exhibit a significant range of pharmacological activities and the most important are their wound-healing, antiinflammatory, diuretic and sedative properties. Hypericin has been also used to treat neurological disorders and traumas. Additionally, its antiviral, antibacterial and antitumor effects are being thoroughly evaluated (Wölfle, Seelinger, Schempp, 2014). Hypericin is a hydroxylated phenantroperlenequinone, a fluorescent red pigment and one of the strongest known plant derived photosensitizer. It induces photocytotoxic activity in vivo and in vitro and 
displays potential as a photosensitizer for photodynamic therapy (Karioti, Bilia, 2010). The contents of hypericin and pseudohypericin vary from species to species $(0.03-$ $0.3 \%$ ) and is sometimes also found to vary within the same species, depending on the plant developmental stage, growing location or harvesting time (Karioti, Bilia, 2010). In some taxa $H$. hirsutum and $H$. empetrifolium only hypericin can be found (Kitanov, 2001) while some other species such as $H$. boissieri, $H$. barbatum, $H$. rumeliacum may contain a 2-4 fold higher amount of hypericins than H. perforatum (Karioti, Bilia, 2010).

In Egyptian folk medicine, another hypericin containing species i.e., $H$. sinaicum $\mathrm{L}$. has been used. This is the endemic species in Sant Katherin Protectorate South Sinai, Egypt also found in North Saudi Arabia that was included in the IUCN red list of threatened plants in 1994 (Boulos, 2002). H. sinaicum is a herbaceous perennial $H$. sinaicum reproduced by seeds and rootstocks and there has been a growing interest to cultivate this plant commercially (Khafagi, Hatab, Omar, 2012). However it is a small plant that grows slowly thus the herb production is low (Omar 2014). Production of valuable secondary metabolites in bioreactors may be considered as an alternative and several successful applications have been demonstrated (Li et al., 2008).

Phytopharmaceutical preparations of Hypericum are usually produced from in vivo grown plants but the limited area of the plant existence, harvesting season, loss of biodiversity, variability in quality, and contamination issues, trigger to search for alternative methods of hypericin production. In phytopharmaceutical industry, one solution could be the utilization of micropropagated plants derived in aseptic conditions (Omar, 2014). In our previously studies we showed that $H$. sinaicum seeds were able to germinate in vitro and the process was more efficient when using the MS medium (Murashige, Skoog, 1962) with full salts strength in comparison to other nutrient media. The ability to micropropagation depended on the treatment with plant growth regulators and nodal or root explants cultured for 3 weeks were the most suitable for callus production and regeneration to shootlets (Khlifa et al., 2016a, b).

Several studies have been carried out to investigate the influence of various factors on the accumulation of secondary metabolites in Hypericum cultures carried out in vitro (Bivadi et al., 2014). Attempts were made to generate populations producing and characterized by maximum concentrations of these bioactive compounds, either in vivo or in vitro cultures. Also $H$. sinaicum has been assessed for its ability to produce hypericin in vitro. Chemical analysis confirmed hypericin presence in callus and in shootlets regenerated indirectly from nodal explants. These materials contained more hypericin than root segments (Khlifa et al., 2016a, b).

Modification of a plant genome through genetic transformation has been shown to be an indispensable tool for crop improvement, investigation of plant functional genomics, genome editing, and synthetic biology. (Hwang, Galvin, Lai, 2015). This approach can be also utilized for the production of bioactive compounds either through redirecting or modifying biosynthesis pathways (Komarovská et al., 2009). Hairy roots can accumulate or elicit large quantities of desired compounds as the effect of enhanced biosynthesis of secondary metabolites due to turning on the transcription of plant defense genes (Ono, Tain, 2011). Hairy roots develop as a result of Agrobacterium rhizogenes infection of injured plants. A. rhizogenes is a well known, soil born, gram negative bacteria possessing a root inducing (Ri) plasmid harboring two transfer (TR and TL) DNA fragments with several sequences of rol and aux loci. These genes are transferred from bacteria to plant cells via a horizontal gene transfer where they are responsible for hairy root morphological and physiological alterations (Komarovská et al., 2009; Koperdakova et al., 2009a). In controlled laboratory conditions, hairy root induction can be stimulated by tissue wounding and subsequent inoculation with $A$. rhizogenes. The developing roots are characterized by the ability to fast growth due to elevated amounts of endogenously synthesized auxins, disturbed geotropism and usually easy to distinguish hairy phenotype (Koperdáková et al., 2009b). Hairy roots excised from the source tissue retain their vigorous growth and exhibit extensive lateral branching when cultured on growth regulator-free media, and can be easily maintained in in vitro culture using either a solid or liquid medium (Li et al., 2008). They also show potential for stable production of various bioactive compounds that can be extracted if desired (Tusevski et al., 2013). Thus plant genetic engineering resulting from the transfer of Ri T- DNAs has been found as an effective indirect way of induction and high level accumulation of plant secondary metabolites using contained systems (Abdi et al., 2017). Induction of hairy roots using transgenesis approach is thus crucial, in particularly for medicinal plants as cultured hairy roots may be a convenient source of industrially important metabolites used in high quality medicinal products (Bafana, Lohiya, 2013). 
Until now, only A. rhizogenes (Komarovská et al., 2009) and biolistic-mediated (Franklin, Oliveira, Dias, 2007) transformation procedures for a few Hypericum species have been applied. In the first successful transformation of $H$. perforatum wild agropine strain $A$. rhizogenes ATCC 15834 was used (Di Guardo et al., 2003). Also, an efficient transformation protocol of this species was reported with $A$. rhizogenes A4M70GUS (Vinterhalter et al., 2006). Prior reports indicated that A. rhizogenes strains and types of explants significantly influenced the induction of hairy roots (Sudha et al., 2012). In addition, A. rhizogenes strain A4-mediated transformation system applied to $H$. perforatum led to the development of hairy root cultures amenable for subsequent shoot regeneration. These transgenic shoots produced naphtodianthrone compounds, and the concentration of hypericin and pseudohypericin was about 12-fold higher than in not transgenic control (Bivadi et al., 2014). However, only few studies have been focused on secondary metabolite production in $H$. perforatum hairy roots (Tusevski et al., 2013) and plants regenerated from them (Koperdáková et al., 2009). Two other Hypericum species (H. tomentosum and $H$. tetrapterum) were also successfully transformed with A. rhizogenes ATCC 15834 and A4 (Komarovská et al., 2009).

To our best knowledge, there is no reports showing successful induction and culture of hairy roots in $H$. sinaicum. In this work we evaluate $H$. sinaicum ability to develop hairy roots that can be considered as potential source of hypericin. We demonstrate susceptibility of $H$. sinaicum explants to $A$. rhizogenes and compare conditions promoting hairy root induction, including the selection of bacterial strain, sonication time, explant type and method of inoculation. The results presented here indicate for the first time that hypericin-rich hairy roots can be obtained and cultured in vitro. The developed method can be helpful in studying regulatory aspects involved in the biosynthesis of important bioactive metabolites in this species.

\section{MATERIAL AND METHODS}

\section{Agrobacterium rhizogenes strains}

Three A. rhizogenes strains A4T (derivative of C58 with pRiA4) (McInnes et al., 1989), A4 (pRiA4) (Moore, Warren, Strobel, 1979), and LBA1334 (derivative of C58 with pRi1855) (Visser et al. 1989) were used. All strains possessed the binary plasmid pBIN-m-gfp5-ER (Haseloff et al. 1997) with T-DNA containing the neomycin phosphotransferase (nptII) gene under the nos promoter control. Additionally, strain A4T, hereinafter denoted as A4T-GUS, harboring the pCambial301 binary plasmid (Hajdukiewicz, Svab, Maliga, 1994) was used. The plasmid T-DNA contained the hygromycin (hptII) resistance gene and the $\beta$-glucuronidase (uidA-int) gene with the castor bean catalase intron preventing glucuronidase expression in bacteria, both genes were under the CaMV 35S promoter control. All plasmids possessed kanamycin resistance gene expressed in bacteria.

\section{A. rhizogens inoculum}

A. rhizogenes strains were cultured on a solidified lysogeny broth (LB) containing $50 \mathrm{mg} / \mathrm{L}$ kanamycin and $50 \mathrm{mg} / \mathrm{L}$ rifampicin at $28{ }^{\circ} \mathrm{C}$. Single colonies were used to inoculate $30 \mathrm{~mL}$ of liquid $\mathrm{LB}$ containing $50 \mathrm{mg} / \mathrm{L}$ kanamycin and were incubated at $28{ }^{\circ} \mathrm{C}$ using a rotary shaker set to $200 \mathrm{rpm}$. An overnight culture was centrifuged at $8000 \mathrm{rpm}$ for $10 \mathrm{~min}$. The pellet of Agrobacterium cells was re-suspended in $2 \mathrm{~mL}$ of liquid Murashige and Skoog macro- and microelement medium with vitamins (Murashige, Skoog, 1962), and $30 \mathrm{~g} / \mathrm{L}$ sucrose, $\mathrm{pH}=5.8$ (MS). The suspension was diluted to OD600 $=0.5$ after the measurement of its optical density using the NanoDropTM 2000c spectrophotometer (Thermo Fisher Scientific, Waltham, USA). The final inoculum was enriched with $100 \mu \mathrm{M}$ acetosyringone (Sigma, St. Louis, USA).

\section{Plant material}

Seeds of Hypericum sinaicum were obtained from Sant Katherin Protectorate South Sinai governorate, Egypt. After surface sterilization they were placed on a solidified MS medium and incubated for four weeks essentially as described before (Khlifa et al., 2016a). Then the seedlings were transferred to a fresh MS medium (one seedling per glass jar) and they were grown for the next 6 weeks. Tobacco (Nicotiana tabacum) in vitro grown plants on the same medium and in the same conditions as $H$. sinaicum was used as the reference material for transformation experiments.

\section{Transformation of explants exposed to a solid mineral medium}

Leaves, nodal segments and root sections were cut and transferred to sterile Petri dishes. Leaves were cut into approx. $5 \mathrm{~mm}$ sections. Nodal segments and roots were 
cut into approx. $15 \mathrm{~mm}$ long fragments and were gently wounded with a scalpel. Explant sections were immersed in $A$. rhizogenes inoculum in $50 \mathrm{~mL}$ Falcon tubes and exposed to sonication treatments for $15 \mathrm{~s}, 30 \mathrm{~s}$, or $60 \mathrm{~s}$ using an ultrasonic bath (Polsonic, Warsaw, Poland). Then the explants were shortly blotted on a sterile filter paper and transferred to a solidified, growth regulatorsfree MS medium with $100 \mu \mathrm{M}$ acetosyringone and cocultivated at $25 \pm 2{ }^{\circ} \mathrm{C}$ in the dark for two days. Then they were transferred to a fresh MS medium with $1 \mathrm{mg} / \mathrm{L}$ IBA, $400 \mathrm{mg} / \mathrm{L}$ cefotaxime to eliminate bacteria and $50 \mathrm{mg} / \mathrm{L}$ kanamycin or $25 \mathrm{mg} / \mathrm{L}$ hygromycin for the selection of transgenic events, and cultured for four weeks at the same conditions. Explants treated with bacteria-free inoculum were considered as a negative control.

\section{Transformation of shoots held in Rockwool cubes}

Sterile Rockwool cubes type AO36/40 (Hummert International, Earth City, USA), commonly used for seed and cutting propagation, were punctured with a pipette tip to its $3 / 4$ depth, placed in a glass jar and soaked with $4 \mathrm{~mL}$ of inoculum. Single shoots were inserted in to the cube wholes after roots were cut-off from plants already grown in vitro. The jars were left open allowing dehydration for a few hours until the first wilt symptoms were noticed. Then cubes were saturated with MS medium and the closed jars were placed in a growth chamber at $25 \pm 2{ }^{\circ} \mathrm{C}$ and $16 / 8 \mathrm{~h}$ photoperiod. Rockwool cubes were checked periodically and MS medium was added when necessary during the culture period. After the appearance of roots, MS medium with addition of $400 \mathrm{mg} / \mathrm{L}$ cefotaxime, $50 \mathrm{mg} / \mathrm{L}$ kanamycin or $25 \mathrm{mg} / \mathrm{L}$ hygromycin, and $1 \mathrm{mg} / \mathrm{L}$ IBA was added when necessary to ensure medium excess in the jar, and the plants were cultured for further two weeks. MS medium without kamanycin and hygromycin was used for control shoots treated with bacteria-free inoculum.

\section{Hairy root culture}

Hairy roots were excised from transformed explants or plants, placed in Petri dishes containing MS medium supplemented with $1 \mathrm{mg} / \mathrm{L}$ IBA and $400 \mathrm{mg} / \mathrm{L}$ cefotaxime, $50 \mathrm{mg} / \mathrm{L}$ kanamycin or $25 \mathrm{mg} / \mathrm{L}$ hygromycin, and incubated at $25 \pm 2{ }^{\circ} \mathrm{C}$ in the dark. Sub-cultures were done every three weeks by transfer to fresh medium. Control, non-transformed roots excised from Rockwool grown shoots were cultured on the same medium free of kanamycin and hygromycin. Additionally, $0.5 \mathrm{~g}$ of hairy root samples were transferred to $100 \mathrm{~mL}$ Erlenmeyer flasks containing $30 \mathrm{~mL}$ MS liquid medium supplemented as described above. Root cultures were maintained on a rotary shaker set to $200 \mathrm{rpm}$ at $25 \pm 2{ }^{\circ} \mathrm{C}$ in the dark.

\section{PCR}

PhireTM Plant Direct PCR kit (Thermo Fisher Scientific, Waltham, USA) was used to perform direct PCR according to the producer's protocol. Aliquots of $0.5 \mu \mathrm{L}$ were used as DNA templates and the PCR reactions were carried out in the final volume of $20 \mu \mathrm{L}$. Three primer pairs were used to detect $A$. rhizogenes rolD, aux 1 and aux 2 genes in transgenic material (Table I). The reaction conditions were: hot start at $94{ }^{\circ} \mathrm{C}$ for 4 min followed by 30 cycles of denaturation at $94{ }^{\circ} \mathrm{C}$ for $4 \mathrm{~min}$, annealing at $58{ }^{\circ} \mathrm{C}$ for $1 \mathrm{~min}$, and extension at $72{ }^{\circ} \mathrm{C}$ for $1 \mathrm{~min}$, and the final extension at $72{ }^{\circ} \mathrm{C}$ for $5 \mathrm{~min}$. The amplified products were resolved in $1 \%$ agarose gel, stained by SimplySafe (EURx, nd visualized in UV light.

TABLE I - Nucleotide sequences of PCR primers

\begin{tabular}{llcc} 
Gene & Primer & Nucleotide sequence $\left(\mathbf{5}^{\prime}, \mathbf{3}^{\prime}\right)$ & $\begin{array}{c}\text { Expected length of the } \\
\text { amplified fragment (bp) }\end{array}$ \\
\hline RolD & rolD-for & CTGAGCGTGTGGCTCATG & 101 \\
& rolD-rev & GGAGGTAAAGACGAAGGACAGAG & 198 \\
auxl & aux1-for & CATAGGATCGCCTCACAGGT & \\
& aux1-rev & CGTTGCTTGATGTCAGGAGA & $($ continuing $)$
\end{tabular}


TABLE I - Nucleotide sequences of PCR primers

\begin{tabular}{lllc}
\hline Gene & Primer & Nucleotide sequence $\left(\mathbf{5}^{\prime}, \mathbf{3}^{\prime}\right)$ & $\begin{array}{c}\text { Expected length of the } \\
\text { amplified fragment (bp) }\end{array}$ \\
\hline \multirow{2}{*}{ aux2 } & aux2-for & AACGATAATAGCCCGCTGTG & 217 \\
& aux2-rev & CGTCTTGGGTTTGTGGTTCT & \\
\hline
\end{tabular}

\section{GUS histochemical staining}

Histochemical localization of GUS activity in hairy roots was performed using the 5-bromo-4-chloro3-indolyl glucuronide (x-Gluc) (Duchefa Biochemie, Haarlem, The Netherlands) substrate essentially according to Jefferson et al. (1987) and described in details before (Klimek-Chodacka, Baranski, 2014). Then hairy root pieces were rinsed in $70 \%$ ethanol for 5 min and GUS activity was scored based on tissue blue staining.

\section{HPLC detection and quantification of hypericin}

Hypericin detection and quantification in vitro derived plants (control), root explants and transgenic hairy roots was carried out using HPLC as described before (Khlifa et al., 2016a, b). The reference hypericin standard (Sigma-Aldrich, Munich, Germany) was used to calculate the equation of calibration line $(\mathrm{y}=7020.1 \mathrm{x}$ +15.4 ) with coefficient of determination $\mathrm{R} 2=0.9995$.

\section{Statistical analysis}

Data were subjected to a factorial analysis of variance and then the Tukey multiple comparison test was used for testing significance between means at $p=0.05$. The $t$-test was used for comparison of two means. Frequencies of shoots held in Rockwool cubes and developing hairy roots were compared using a statistical test for significance level between two proportions. Pearson linear correlation coefficients were calculated to assess relationship between hairy root and shoot characters. Experiments were set up in a randomized designed with minimum five replications. Data were processed using CoStat_v6.303 statistical software.

\section{RESULTS}

Development of hairy roots on explants exposed to a solid medium

Control H. sinaicum explants not incubated with A. rhizogenes remained viable on a solid MS medium throughout the culture period. Leaf and stem explants developed mainly new shoots while root explants enlarged and developed callus. In $A$. rhizogenesmediated explants callogenesis was limited and the development of new shoots delayed. These explants were capable of hairy root formation that were easily distinguished by their characteristic hairy phenotype and disturbed geotropism (Figure 1). Usually several hairy roots developed from one explant but some explants did not respond. In particular, leaf explants showed necrosis that could restrict hairy root development.

We assessed explant susceptibility to four $A$. rhizogenes strains and, on average, $66-72 \%$ of explants developed hairy roots independent on whether they were co-cultivated with either A4 or any of the A4T strains ( $p=$ $0.119)$. In contrast, hairy roots were observed significantly less frequently $(\mathrm{p}<0.001)$ on LBA1334 treated explants (3.3\%). However, the LBA1334 strain virulence was confirmed $(\mathrm{p}<0.001)$ by comparing reaction of $H$. sinaicum and tobacco explants, the later used as a reference material. Independent on the explant type, on average, $80.6 \%$ of tobacco explants produced hairy roots confirming LBA1334 was able to transform plant cells efficiently but was hardly able to transform $H$. sinaicum .

$H$. sinaicum has never been used for genetic transformation hence we compared three explant types in their susceptibility to three (A4, A4T and A4T-GUS) strains and their suitability for further hairy root production. In general, explants of different types responded to $A$. rhizogenes with various efficiencies $(\mathrm{p}<0.001)$ and most stem explants $(83.6 \%)$ produced hairy roots 1.45 -fold more frequently than leaf explants (57.7\%). Root explants 
responded less frequently (68.3\%) than stem explants. This relationship was observed for all three strains although for the A4T strain there was no difference between root and stem explants (Figure 2). Notably, tobacco leaf and stem explants were equally highly susceptible to the LBA1334 strain. Detailed comparison indicated that the highest percentage of $H$. sinaicum explants developing hairy roots was obtained after stem segments co-cultivation with the A4 and A4T-GUS strains ( $88.3 \%$ and $91.7 \%$, respectively). The A4 strain and both A4T strains considered together were equally efficient $(p=0.622)$ in transformation of leaf, root and stem explants (Figure 3).

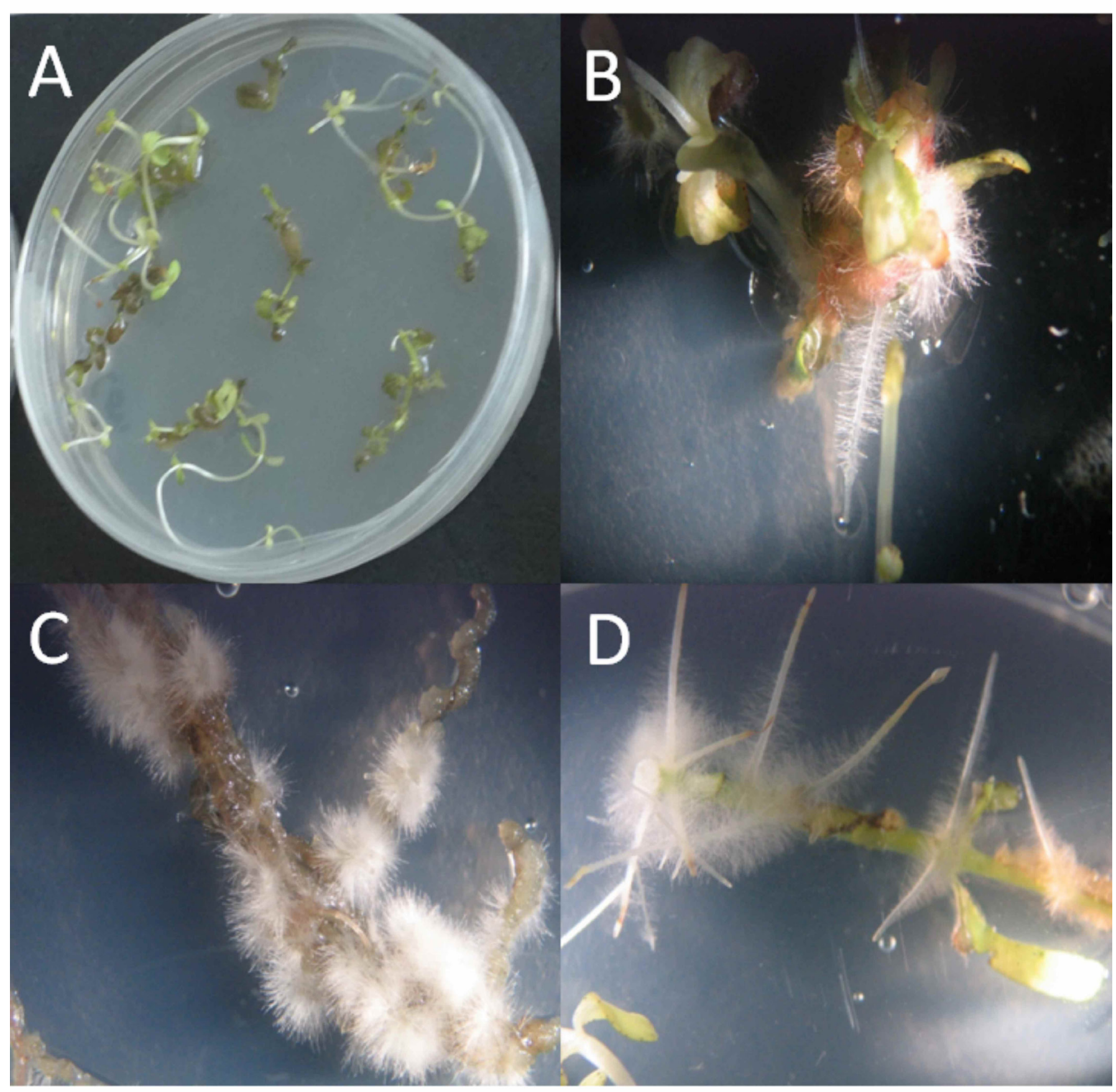

FIGURE 1 - Development of hairy roots on H. sinaicum explants. Control stem explants not inculated with bacteria (A), leaf (B), root (C) and stem (D) explants inoculated with the A4 A. rhizogenes strain and exposed to a solid MS medium. 


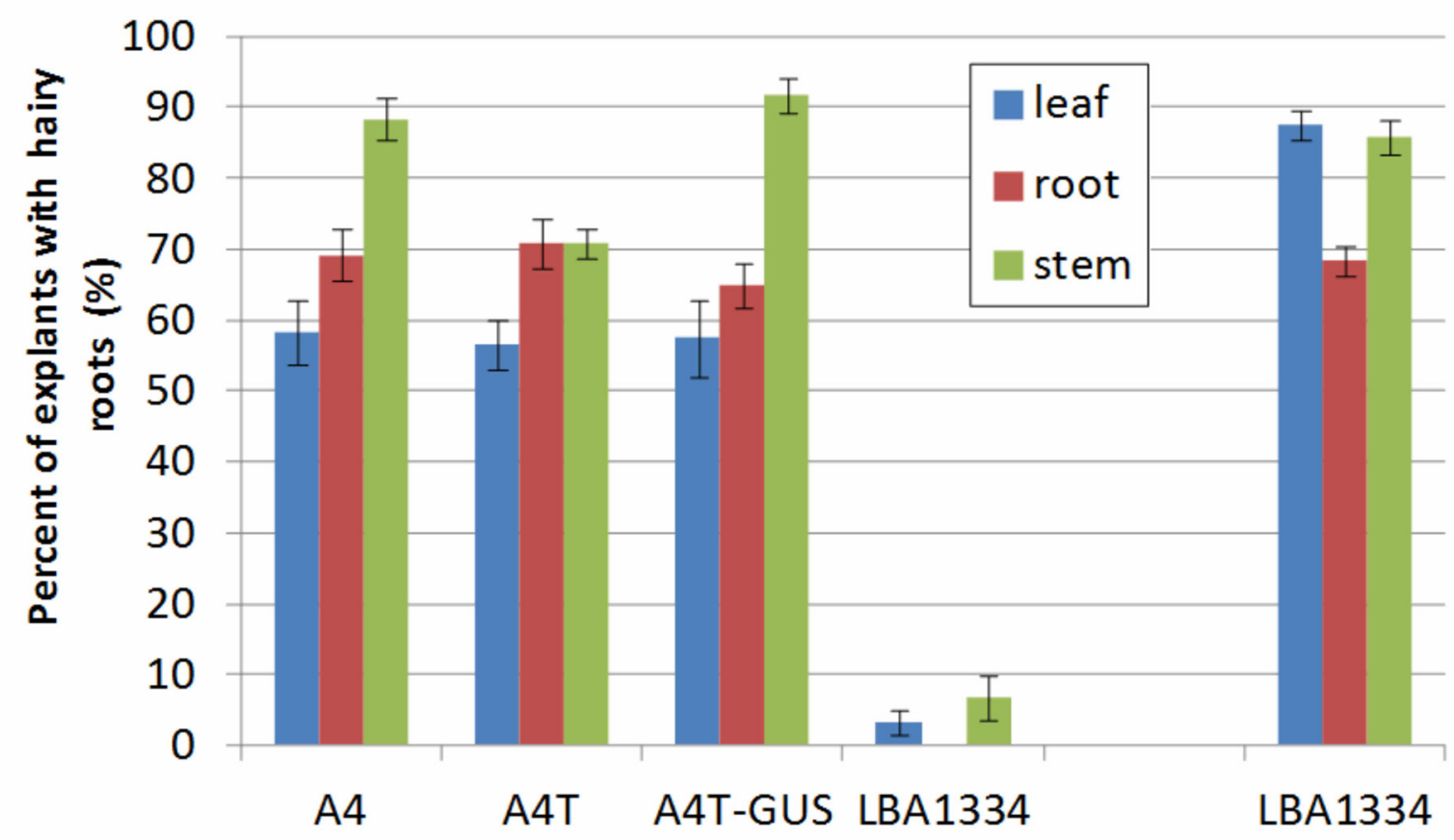

FIGURE 2 - Percentage of $H$. sinaicum explants exposed to a solid MS medium and developing hairy roots four weeks after transformation with four $A$. rhizogenes strains. Additionaly, percentage of tobacco explants with hairy roots after inoculation with the LBA1334 strain. Whiskers - standard error.

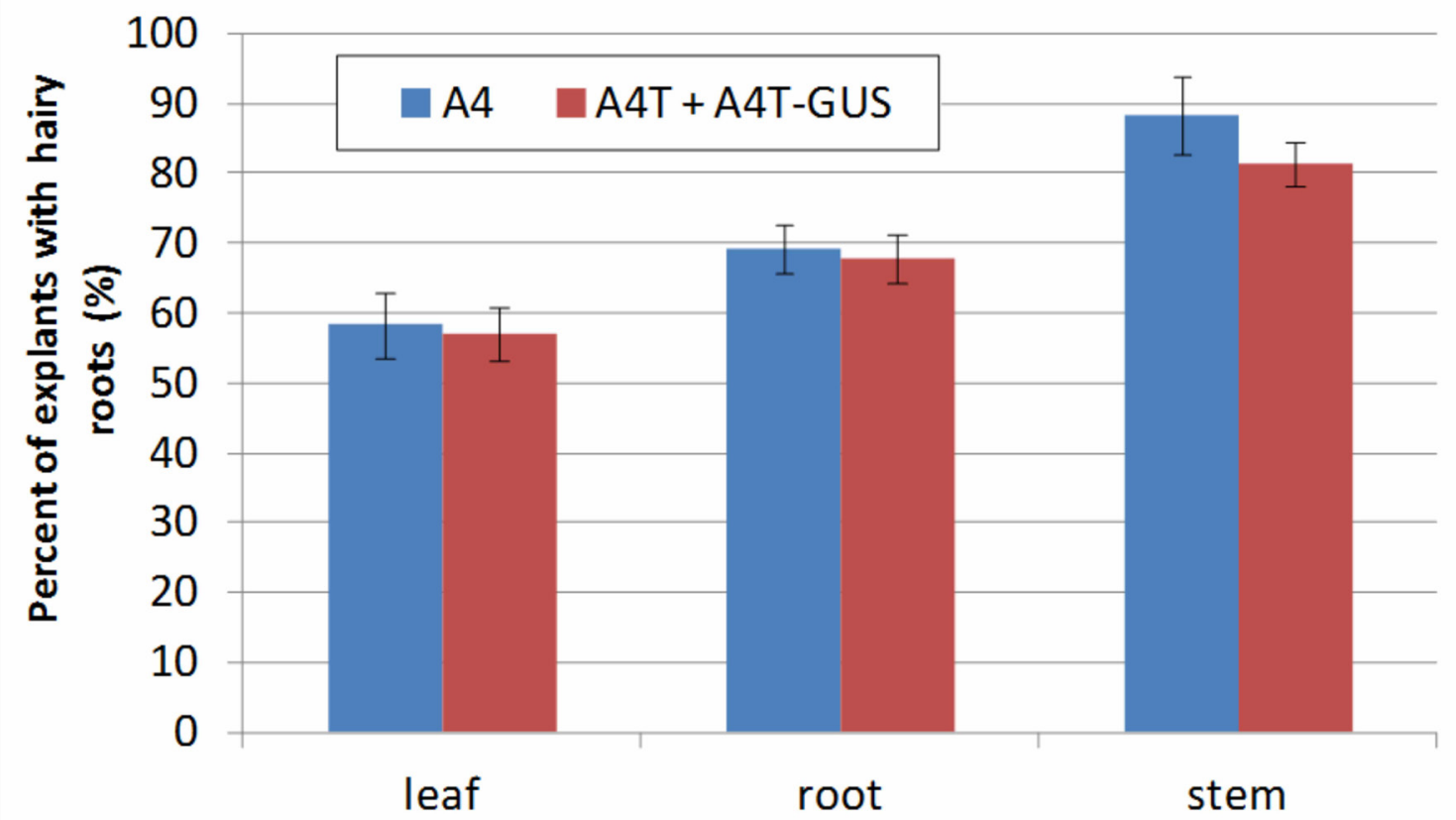

FIGURE 3 - Effectiveness of the A4 and A4T strains in the induction of hairy root development on H. sinaicum explants exposed to a solid MS medium. A4T - combined data for explants inoculated with the A4T and A4T-GUS strains. Whiskers - standard error. 
The highest response was observed when stem explants were sonicated in $A$. rhizogenes inoculum for $30 \mathrm{~s}$ or $60 \mathrm{~s}$ (Figure 4). Longer sonication time increased the efficiency of stem transformation $(\mathrm{p}=$ 0.004) also when A4T strain was used. This treatment stimulated efficient response of leaf and root explants independently on the bacteria strain used. The most pronounced change was observed for leaf explants. The extension of sonication time from $15 \mathrm{~s}$ to $60 \mathrm{~s}$ doubled the percentage of responding explants. For root explants, the change from $15 \mathrm{~s}$ to $30 \mathrm{~s}$ had no significant effect, while after $60 \mathrm{~s}$ sonication the percentage of responding explants was 1.46-fold higher than after $15 \mathrm{~s}$ treatment.

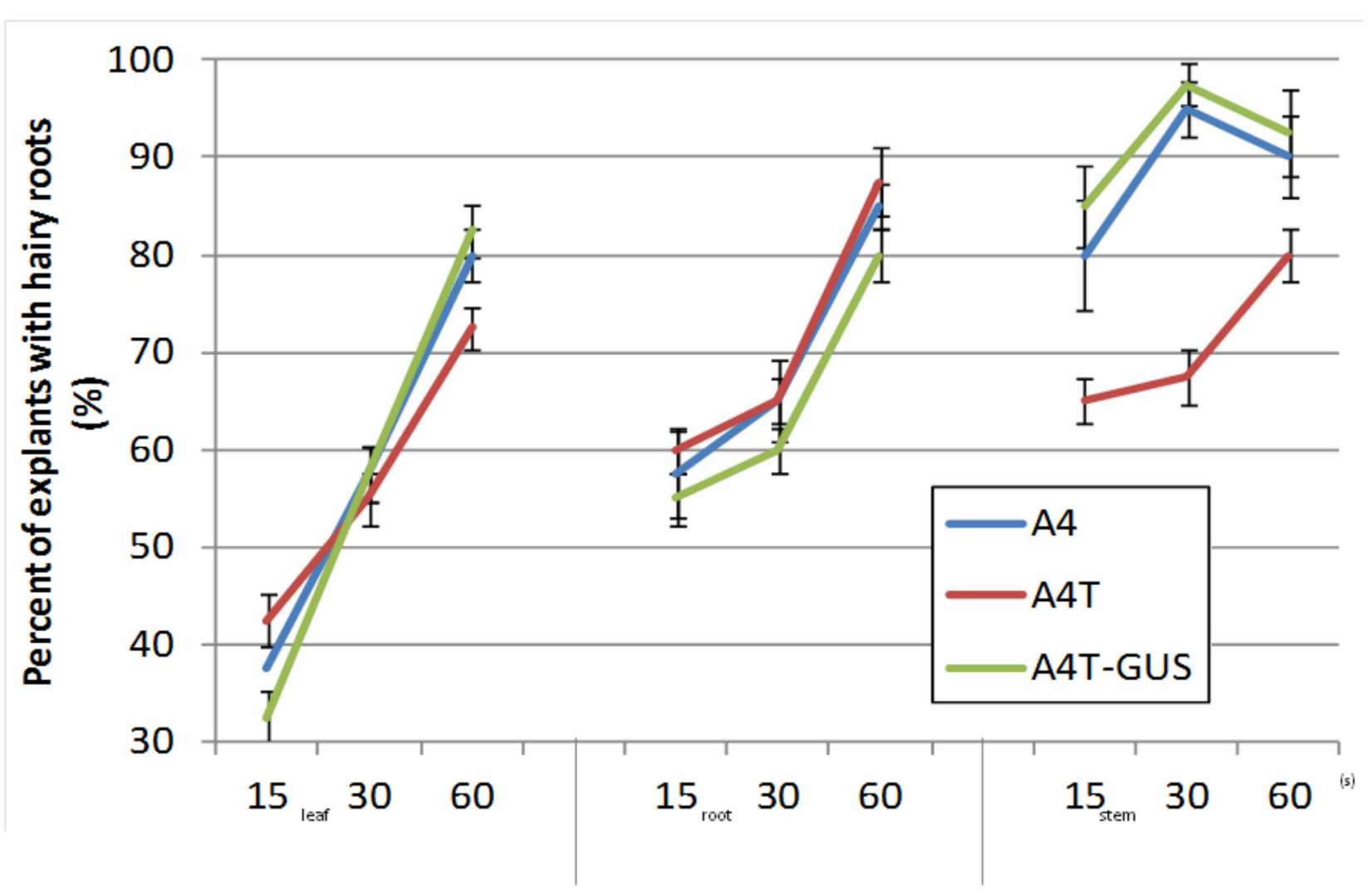

FIGURE 4 - Effect of sonication time on the percentage of $H$. sinaicum explants developing hairy roots depending on the explant type and $A$. rhizogenes strain used. Whiskers - standard error.

\section{Development of hairy roots from shoots inoculated in Rockwool cubes}

Rockwool cubes were used to hold shoots upright after their root system was cut-off and to enable inoculum transfer to basal shoot part. The shoots inserted in cubes soaked with inoculum remained vigorous while being closed in sterile jars and they continued their growth developing new leaves and shoots from axillary buds. After ten days, first hairy roots emerged on Rockwool cube sides (Figure 5). They elongated fast and showed typical hairy phenotype. Four-week-old hairy roots were branched and overgrew the cubes. They were produced by shoots co-cultured with all four $A$. rhizogenes strains used although with various efficiencies. All shoots incubated with LBA1334 produced hairy roots (Table II), unlike in transformation experiments with explants inoculated using this strain and exposed to a solid medium. Only a half or less shoots that were incubated with both A4T and A4T-GUS strains developed hairy roots. The response may remain underestimated as hairy roots might develop inside the cube and did not reach its surface making the observation of hairy roots not possible. 


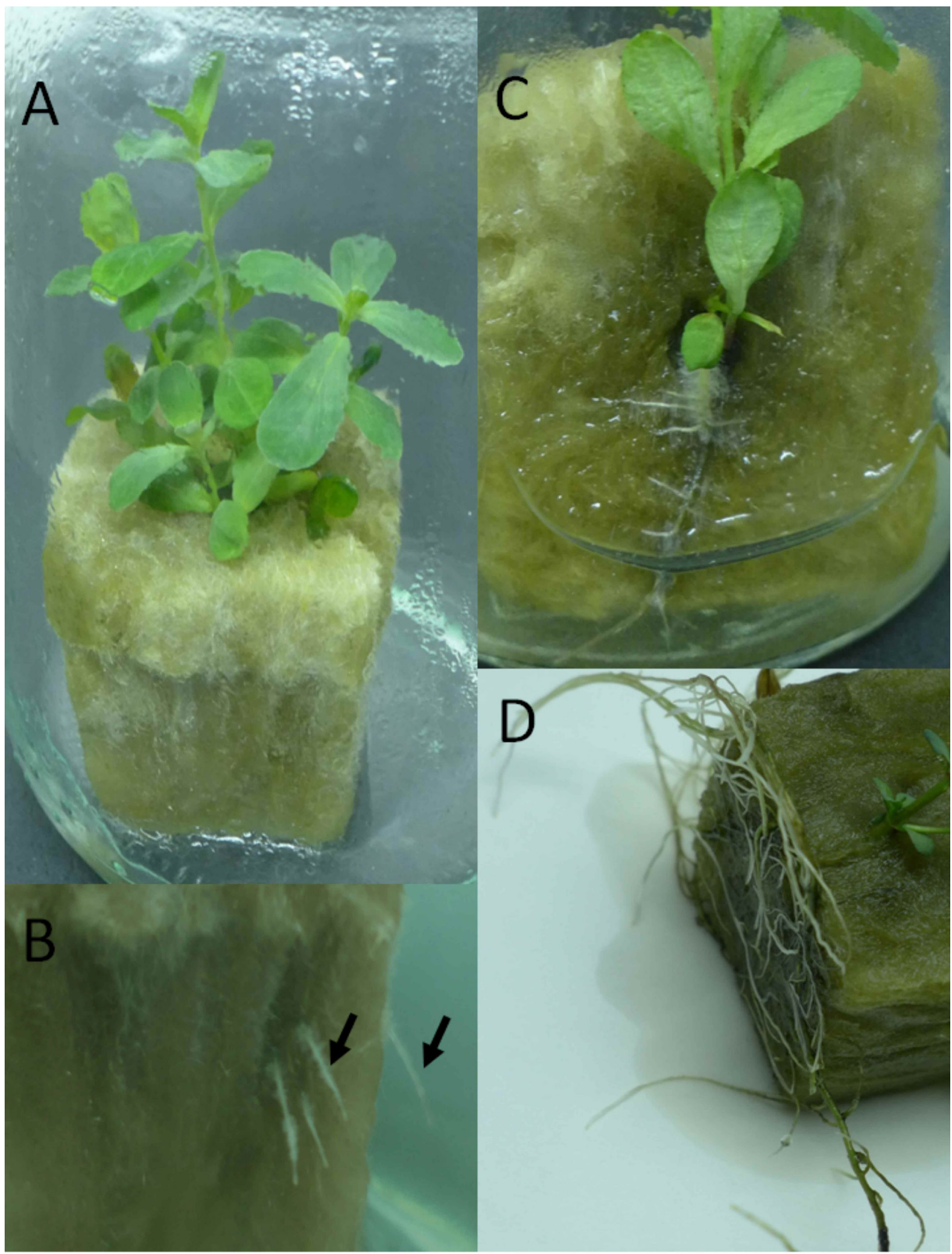

FIGURE 5 - Hairy root development on $H$. sinaicum shoots held in Rockwool cubes in vitro and inoculated with the A4 $\mathrm{A}$. rhizogenes strain. Control shoots after a six-week-culture (A), hairy roots appearing at Rockwool cube sides 10 days after inoculation (B), branched hairy root (C), Rockwool cube overgrown by hairy roots three weeks after shoot inoculation (D). 
TABLE II - Efficiency of hairy root development by shoots inoculated in Rockwool cubes, and the performance of hairy roots and responding shoots after three-week culture (mean values with standard errors)

\begin{tabular}{|c|c|c|c|c|c|c|c|c|c|c|c|c|c|c|}
\hline \multirow{3}{*}{$\begin{array}{l}\text { Strain } \\
\text { LBA1334 }\end{array}$} & \multirow{2}{*}{\multicolumn{2}{|c|}{$\begin{array}{l}\text { Proportion of } \\
\text { shoots with } \\
\text { hairy roots }\end{array}$}} & \multicolumn{6}{|c|}{ Hairy roots } & \multicolumn{6}{|c|}{ Shoots with hairy roots } \\
\hline & & & \multicolumn{3}{|c|}{ elongation (cm) } & \multicolumn{3}{|c|}{ no. of branches } & \multicolumn{3}{|c|}{ elongation (cm) } & \multicolumn{3}{|c|}{ no. of branches } \\
\hline & 1.0 & $a^{*}$ & 6.6 & \pm 0.2 & a & 10.9 & \pm 0.3 & $\mathrm{a}$ & 8.8 & \pm 0.3 & a & 2.5 & \pm 0.2 & $\mathrm{a}$ \\
\hline A4 & 0.7 & $\mathrm{ab}$ & 6.5 & \pm 0.1 & a & 9.7 & \pm 0.5 & ab & 7.3 & \pm 0.2 & $\mathrm{~b}$ & 2.1 & \pm 0.1 & ab \\
\hline A4T-GUS & 0.5 & $\mathrm{bc}$ & 4.0 & \pm 0.5 & $\mathrm{~b}$ & 8.0 & \pm 1.4 & bc & 6.7 & \pm 0.3 & bc & 1.6 & \pm 0.2 & bc \\
\hline $\mathrm{A} 4 \mathrm{~T}$ & 0.3 & $\mathrm{c}$ & 4.5 & \pm 0.2 & $\mathrm{~b}$ & 6.7 & \pm 0.3 & c & 6.2 & \pm 0.1 & c & 1.3 & \pm 0.3 & c \\
\hline Control & 0.0 & - & 0.5 & \pm 0.2 & ** & 0.0 & - & & 2.8 & \pm 0.2 & ** & 1.6 & \pm 0.2 & $* *$ \\
\hline
\end{tabular}

* Means followed by the same letter do not differ significantly at $\mathrm{p}=0.05$

${ }^{* *}$ Non-transgenic roots and control shoots

Control shoots did not produce hairy roots although some of them developed hair-free roots after prolonged culture. The root elongation in control plants was slow, $0.5 \mathrm{~cm}( \pm 0.2 \mathrm{~cm}$ std. err.) in three weeks, and no root branching was observed (Table II). In contrast, hairy roots elongated on average by $5.8 \pm 0.3 \mathrm{~cm}$ in three weeks and they produced many branch roots. Hairy roots produced by shoots co-cultivated with LBA1334 and A4 strains grew faster, and developed 8 to 12 branches while those co-cultivated with A4T and A4TGUS strains grew slower and had lower tendency for branching (3 to 11 branches). Thus LBA1334 and A4 treated plants had finally better developed system of hairy roots, and they were more vigorous having tendency for the development of more lateral shoots that also elongated faster (Table II). The A4T and A4T-GUS treated shoots showed similar tendency for branching as the control. Correlations between the percentage of shoots responding to Agrobacterium inoculation, root branching, shoot elongation and shoot branching were very high $(\mathrm{r}>0.9)$. Correlation coefficients between these variables and hairy root elongation were slightly lower and ranged between 0.79 and 0.87 .

\section{Culture of excised hairy roots}

Hairy roots developing on leaf, stem and root explants, and on shoots held in Rockwool cubes were excised 3-4 weeks after inoculation and their fragments of approx. 1-2 cm in length were placed on the selection media. Hairy roots continued their growth on antibiotic enriched media confirming they acquired resistance to either kanamycin or hygromycin after A. rhizogenesmediated transformation (Fig. 6). Independently on the bacteria strain used for inoculation, the developed clones showed similar ability for root elongation. Clones obtained after transformation with the A4 and LBA1334 strains maintained their high ability for branching $(10.8 \pm 0.4$ and $11.8 \pm 0.2$ root branches, respectively) only slightly higher than clones after transformation with both A4T and A4T-GUS strains $(9.2 \pm 0.4$ and $9.4 \pm 0.2$, respectively). Not transformed roots from control plants did not grow, bleached and finally died on the selection media.

Hairy roots transferred to a liquid medium containing selection antibiotics exhibited rapid elongation and pronounced lateral branching. The most efficient biomass production was observed for clones derived after $H$. sinaicum inoculation with the LBA1334 strain. The mean biomass $(4.7 \pm 0.3 \mathrm{~g})$ obtained after one-week culture was two-fold higher than the mean biomass of clones derived after using other strains that ranged from 1.8 to $2.9 \mathrm{~g}$.

\section{Molecular confirmation of hairy root phenotype}

Hairy root phenotype was expected as a result of $A$. rhizogenes T-DNAs transfer to $H$. sinaicum. Hairy root clones were thus verified for the presence of rolD and two 
aux, aux1 and aux2, genes localized on TL-DNA and TR-DNA of $A$. rhizogenes Ri plasmid, respectively. PCR products of approx. 100, 200 and $220 \mathrm{bp}$ were identified after electrophoresis in agarose that corresponded to the expected lengths for amplified fragments of rolD (101 bp), aux1 (198 bp) and aux2 (217 bp) genes, respectively (Fig. 7). The same product lengths were obtained using control DNA from transgenic tobacco while no products were detected for the non-transformed roots.

The use of the A4T-GUS strain containing uidA gene additionally enabled validation of functional gene expression in hairy roots thus successful gene transfer from bacteria to $H$. sinaicum. Hairy root samples collected from clones derived after inoculation with this strain were used for histochemical staining to detect GUS activity. The expected blue staining was observed only in transformed roots whereas control roots did not show altered pigmentation (Fig. 7). The root apical region and central cylinder were stained the most intensely although the intensity of blue color varied from faint to strong.

\section{Hypericin content in hairy roots}

The presence of main naphtodianthrone (hypericins) in $H$. sinaicum was determined in hairy roots. Peak positions in chromatogram obtained from HPLC analysis corresponded to those obtained for the reference compound confirming hypericin presence in hairy roots (Figure 8). The signal intensity for hairy root sample was high and hypericin contents estimated based on the reference standard line was $39.430 \mu \mathrm{g} / \mathrm{g}$ dry weight. Hypericin content estimated for the intact plant and non-transformed root explants were lower, 17.096 $\mu \mathrm{g} / \mathrm{g}$ and $2.538 \mu \mathrm{g} / \mathrm{g}$ dry weight, respectively.

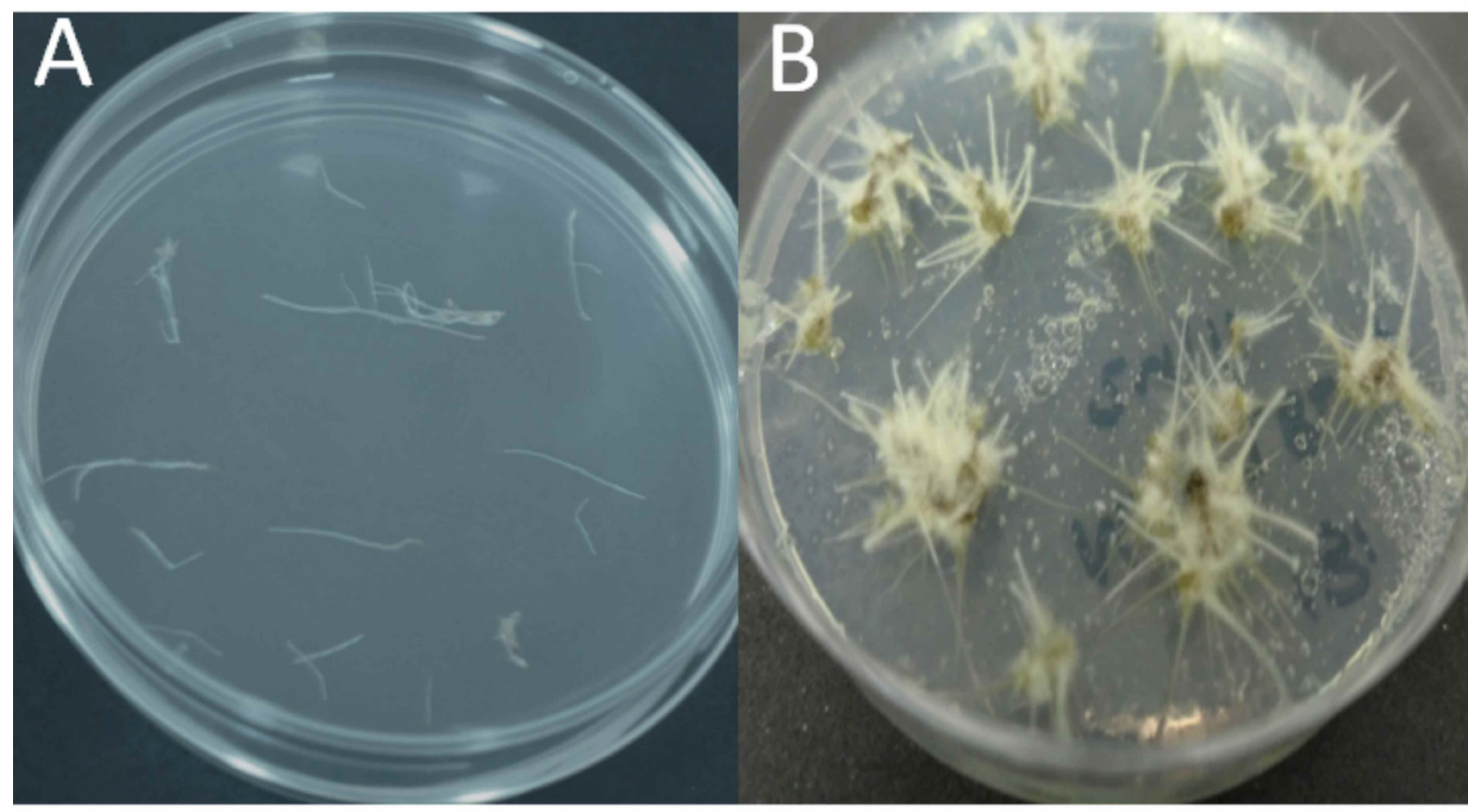

FIGURE 6 - Four-week-old root clones on the kanamycin selection medium. Not developing root fragments taken from the control, not transformed plant (A), intensively growing hairy root clones obtained from explants transformed with the A4 $A$. rhizogenes strain (B). 


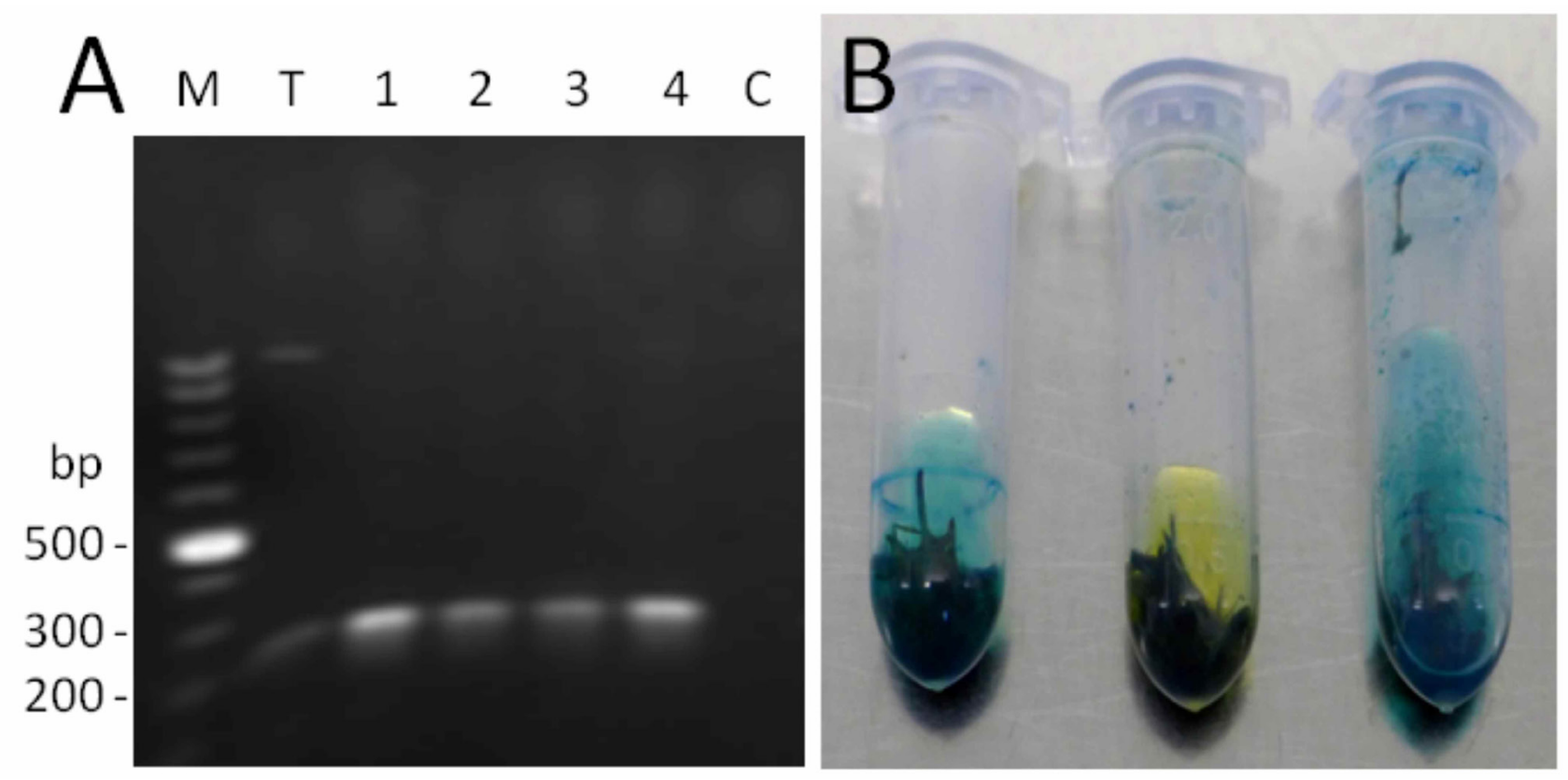

FIGURE 7 - Verification of horizontal gene transfer from A. rhizogenes to H. sinaicum hairy roots. Presence of the expected 198 bp PCR amplified fragment of auxl gene in hairy roots after transformation with A. rhizogenes strains. Lane M - GeneRuler DNA Ladder Mix, lane T - reference DNA from tobacco transformed with the LBA1334, lanes 1-4 - DNA from H. sinaicum hairy roots after transformation with A4T, A4, LBA1334, and A4T-GUS, lane C - DNA from control, not transformed $H$. sinaicum plant (A). Blue staining resulting from the uidA gene transfer from the A4T-GUS A. rhizogenes strain to hairy roots and consecutive GUS activity. Unstained roots from the control, not transformed H. sinaicum plant are in the middle tube (B).

\section{DISCUSSION}

Genetic transformation of $H$. sinaicum has not been performed till now. Several methods were applied to modify $H$. perforatum including particle bombardment and Agrobacterium-mediated transformation with various success but the possibility of induction of hairy roots was shown (Franklin, Oliveira, Dias, 2007; Vinterhalter et al., 2006). In this work we show for the first time the successful $A$. rhizogenes-mediated transformation of $H$. sinaicum and the ability of the obtained hairy roots to biosynthesize hypericin, a plant metabolite of pharmaceutical significance. The results obtained indicate that different bacterial strains can be used for hairy root induction in $H$. sinaicum although with various effectiveness depending on the applied method and explant type. All A. rhizogenes strains used led to hairy root induction and hairy roots were observed in 10 to 30 days after inoculation that is a common response time observed in other species. However, we have found that shoots held in the Rockwool cubes developed hairy roots much faster than excised explants. The major advantage of the method relying on the use of Rockwool cubes is thus its rapidity and technical simplicity. In consequence, the production of transgenic roots takes only a few weeks instead of a few months when excised explants exposed to a mineral solid medium are inoculated. The major limitation of this approach is that, since shoots remain not transformed, the developing plants are composite and their maintenance either by micropropogation or self-fertilization is aimless. Thus hairy root cultures have to be established by excising transgenic root segments independent on whether the shoots or explants were inoculated. We have demonstrated that the excised transgenic root segments may be successfully cultured for biomass production. It is also known that hairy roots may exhibit ability to organogenesis that circumvent limitations rising from the use of hairy root culture if plant production is required (Crane et al., 2006).

The choice of bacterial strain for efficient DNA horizontal transfer is important and has been demonstrated before (Gilbert et al., 1996). We have used strains differing in their Ri plasmids but also in 

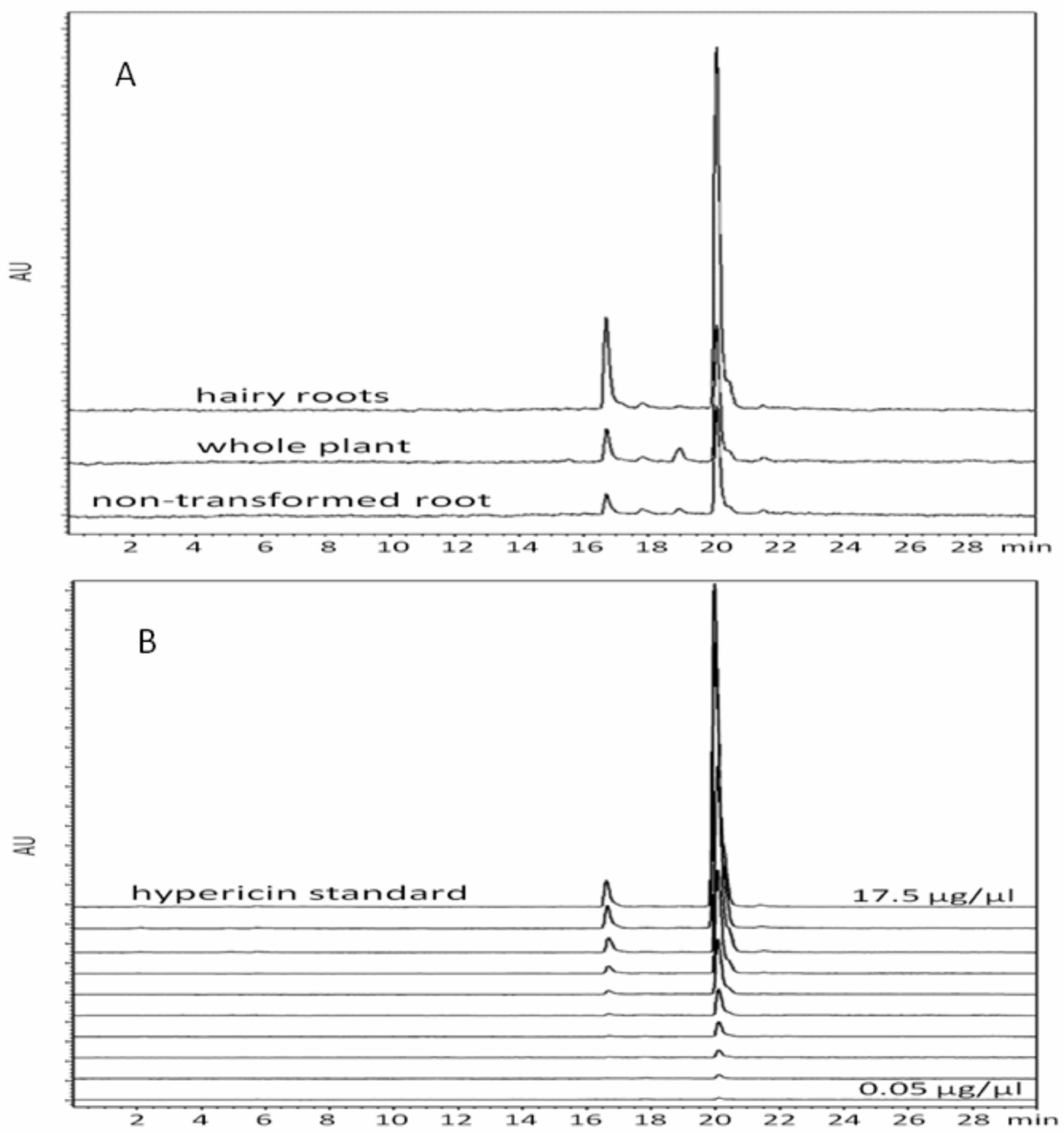

FIGURE 8 - HPLC detection of hypericin in H. sinaicum hairy roots and plant. Hypericin characteristic peaks in chromatograms for samples of hairy roots and control, not transformed whole plant and its roots (A). Quantitative analysis of hypericin standard applied in the range $0.05-17.5 \mu \mathrm{g} / \mu \mathrm{L}(\mathrm{B})$. 
chromosomal background. The A4T and LBA1334 strains are derivatives of the C58 strain thus they both possess A. tumefaciens chromosome in contrast to the A4 strain with $A$. rhizogenes chromosome. Transgenesis is a process requiring interaction of virulence genes located in the plasmid and chromosomal genes thus genetic background may be essential (Hardegger, Sturm, 1998). It was demonstrated that in carrot the A4T and LBA1334 strains stimulated hairy root production with higher frequency than the A4 strain that indicates advantageous role of the C58 chromosomal background (Baranski, Klocke, Schumann, 2006). Our results indicate that strains with any of the used chromosomal context can successfully induce hairy roots in H. sinaicum.

The transformation efficiency is also species specific as demonstrated for two Hypericum species using $A$. rhizogenes wild type strains. The inoculation of $H$. tomentosum with the 15834 strain resulted in $44 \%$ efficiency while the use of A4 strain was less effective (35\%). Much more pronounced differences were observed for $H$. tetrapterum i.e., $73 \%$ and $13 \%$, respectively (Komarovská et al., 2009). Also, higher susceptibility of $H$. perforatum explants was reported when they were transformed with the 15834 strain than with the A4 strain (Bivadi et al., 2014; Di Guardo et al., 2003). However, we have not observed differences between strains used for $H$. sinaicum explant transformation except of LBA1334 was not able to transform either shoot, leaf or root explants. To ensure the strain did not lost its virulence we performed routine screening using tobacco explants and confirmed that LBA1334 remained highly virulent. Thus $H$. sinaicum explants were not susceptible to this strain despite LBA1334 was able to transform another species. Notably, the same strain was highly effective in hairy root induction when shoots held in Rockwool cubes were inoculated. Both A4 and A4T strains harbored pRiA4 plasmid while the LBA1334 strain had pRi1855 plasmid. Previous reports in carrot showed their similar efficiency in DNA transfer when they were provided in the C58 chromosomal context (Baranski, Klocke, Schumann, 2006) but in $H$. sinaicum transformation bacteria with the pRi1855 plasmid seemed more effective when it was co-cultivated with injured shoot base rather than with excised explants. This phenomenon may be due to a longer co-cultivation of shoots with bacteria as no antibiotics were added until hairy roots emerged but also tissue type may be significant. The excised small fragments of leaves, stem or roots are highly injured in contrast to the whole stem that remains vigor and easily commence further growth despite the root system is removed. The differences in the secondary metabolite release affecting bacterial virulence is thus highly probable but requires further confirmation.

We found also that shoots and the excised stem explants were more sensitive to $A$. rhizogenes than leaf and root explants. These results indicate that $H$. sinaicum plant organs may contain different compounds, or their contents, affecting the transformation process. Various responses of different plant tissues to $A$. rhizogenes were reported by (Abdi et al., 2017). Root and leaf segments of both $H$. tomentosum and $H$. tetrapterum species were used for transformation experiments with two $A$. rhizogenes wild-type, ATCC15834 and A4, agropine strains, but only the root segments were capable of transgenic hairy root formation (Komarovská et al., 2009). Also the Agrobacterium viability decreased during co-cultivation with $H$. perforatum flowers and leaves containing hyperforin and hypericin of antibacterial activity (Franklin, Oliveira, Dias, 2007). Stems containing usually less bioactive compounds may thus be less toxic to Agrobacterium and more suitable material for agroinfection. Despite that, not only shoots but also leaves, although with a lower efficiency, can be still prone to agroinfection as shown by us for $H$. sinaicum supporting earlier observations for $H$. perforatum by Vinterhalter et al. (2006) and Di Guardo et al. (2003).

The inoculation and co-cultivation time considerably affect transformation success thus they should be adjusted taking into account bacteria virulence and the explant type used. Longer co-cultivation time is recommended to ensure bacteria attachment to plant cell and T-DNA transfer. The comparison of three inoculation (15, 30 and $45 \mathrm{~min}$ ) and two co-cultivation (24 and $72 \mathrm{~h}$ ) times applied to $H$. perforatum showed that the percentage of hairy roots declined with shorter inoculation and co-cultivation time (Bivadi et al., 2014). However, a prolonged co-culture often results in bacteria overgrowth that destroys plant material thus is avoided. To promote agroinfection in shorter cocultivation time an ultrasound treatment can be applied to explants. During sonication-assisted Agrobacteriummediated transformation (SAAT) plant tissue is partially disrupted that help bacteria intracellular penetration, enlarge contact surface and enable their direct contact with larger number of cells. Moreover, micro wounding of cells enables secretion of phenolic compounds enhancing agroinfection (Pathak, Hamzah, 
2008). It was also demonstrated that short ultrasound treatment is the most efficient when applied to explants already immersed in the inoculum (Klimek-Chodacka, Baranski, 2014). We therefore compared three sonication times and have shown that SAAT stimulates hairy root induction independent on the explant type and bacteria strain used. Actually, $60 \mathrm{~s}$ sonication doubled the transformation efficiency of leaf explants while for stem explants $30 \mathrm{~s}$ treatment was also effective.

A. rhizogenes-mediated transformation results in the hairy roots phenotype accompanied by altered plant morphology and changes in biosynthetic ability (Koperdáková et al., 2009a, b). The transgenic status of the obtained hairy roots was confirmed by PCR using two sets of pRi genes, which are involved in the root induction process; aux genes located in the TR region of the pRi T-DNA and rol (root loci) genes of the TL region (Jouanin, 1984). Aux genes provide transformed cells with an additional source of auxins but they do not seem essential for developing hairy root disease (Chriqui et al., 1996). However, rol genes have functions that are most likely other than that of producing mere alterations in plant hormone concentrations (Nilsson, Olsson, 1997). Finally, Trovato et al. (2001) found that, in cells transformed by agropine plasmids, the RolD protein may provoke a stress response through increased proline production, which may further influence cell division and appears to specifically induce flowering. Proline may also increase the biosynthesis of glycoproteins (rich in hydroxyproline), the cell wall structural components involved in the regulation of cell division. Thus hairy roots often have modified metabolism that may be advantageous when altered biosynthesis of the secondary metabolites is expected. Hairy root cultures have been shown to be an efficient mean of producing secondary metabolites that are normally biosynthesized in roots of growing plants. A. rhizogenes strains exhibit various stimulating effects on the induction and growth of hairy roots, and on the production of secondary metabolites as demonstrated for example in case of lignan biosynthesis in Linum tauricum ssp. (Ionkova, Fussm, 2009). Hairy root system developed from root segments of in vitro grown $H$. perforatum seedlings after co-cultivation with the $A$. rhizogenes A4 strain was utilized to identification and quantification of the secondary metabolite xanthone (Tusevski et al., 2013). Our research led to the development of hairy root culture that was characterized by high hypericin content. The amounts identified were higher than in plant organs making the system an attractive alternative for hypericin production. That may be of particular importance as production in contained conditions like bioreactors will not require cultivation and utilization of endangered $H$. sinaicum.

\section{CONFLICT OF INTEREST}

The authors declare that they have no conflict of interest.

\section{ACKNOWLEDGEMENT}

This research was supported by cooperation between Science and Technology Development FundShort Term Fellowship (STDF-STF), Egypt; ID: (6548); STDF, Project ID: (82) and the Ministry of Science and Higher Education of the Republic of Poland.

\section{REFERENCES}

Abdi N, Uliaie ED, Bandehagh A, Aharizad S. Effect of Agrobacterium rhizogenesis on hairy roots induction in Fennel (Foeniculum vulgaremiller MILLER). J Exp Biol Agricult Sci. 2017;5(3):384-391.

Bafana A, Lohiya R. Diversity and metabolic potential of culturable root-associated bacteria from Origanum vulgare in sub-Himalayan region. World J Microbiol Biotechnol. 2013;29(1):63-74.

Baranski R, Klocke E, Schumann G. Green fluorescent protein as an efficient selection marker for Agrobacterium rhizogenes mediated carrot transformation. Plant Cell Rep. 2006;25(3):190-197.

Bivadi V, Zakaria AR, Zare N, Yazdani B. Effects of different tissue culture conditions in Hairy roots induction in Hypericum perforatum L. Intl J Agri Crop Sci. 2014;7(9):646-653.

Boulos L. Flora of Egypt. Cairo, Egypt: Al Hadara Publishing; 2002; v. 3, p. 373.

Chriqui D, Guivarch A, Dewitte W, Prinsen E, van Onkelen H. Rol genes and root initiation and development. Plant Soil. 1996;187(1):47-55.

Crane C, Wright E, Dixon RA, Wang ZY. Trangenic Medicago truncatula plants obtained from Agrobacterium tumefaciens transformed roots and Agrobacterium rhizogenestransformed hairy roots. Planta. 2006;223(6):1344-1354.

Di Guardo A, Čellárová E, Koperdáková J, Pistelli L, Ruffoni, B, Allavena A, Giovannini A. Hairy roots induction and plant 
regeneration in Hypericum perforatum L. J Genet Breed. 2003;57:269-278.

Franklin G, Oliveira M, Dias ACP. Production of transgenic Hypericum perforatum plants via particle bombardmentmediated transformation of novel organogenic cell suspension cultures. Plant Sci. 2007;172(6):1193-1203.

Gilbert SF, Optiz JM, Raff RA. Resynthesizing evolutionary and developmental biology. Dev-Biol.1996;173(2):357-372.

Hajdukiewicz P, Svab Z, Maliga P. The small versatile pPZP family of Agrobacterium binary vectors for plant transformation. Plant Mol Biol. 1994;25(6):989-994.

Hardegger M, Sturm A. Transformation and regeneration of carrot (Daucus carota L.). Mol Breed. 1998;4(2):119-127.

Haseloff J, Siemering KR, Prasher DC, Hodge S. Removal of a cryptic intron and subcellular localization of green fluorescent protein are required to mark transgenic Arabidopsis plants brightly. Proc Natl Acad Sci USA. 1997;94(6):2122-2127.

Hwang HH, Galvin SB, Lai EM. Editorial: Agrobacterium biology and its application to transgenic plant production. Front Plant Sci. 2015;6:265.

Ionkova I, Fuss E. Influence of different strains of Agrobacterium rhizogenes on induction of hairy roots and lignan production in Linum tauricum ssp. tauricum. Pharmacognosy Mag. 2009;5(17):14-18.

Jefferson R. Assaying chimeric gene in plants: the GUS gene fusion system. Plant Mol Biol Rep. 1987;5(1):387-405.

Jouanin L. Restriction map of an agropine-type Ri-plasmid and its homologies with Ti-plasmids. Plasmid. 1984;12(2): 91-102.

Karioti A, Bilia AR. Hypericins as potential leads for new therapeutics. Int J Mol Sci. 2010;11(2):562-594.

Khafagi AO, Hatab EE, Omar AK. Challenges towards Hypericum sinaicum conservation in South Sinai, Egypt. Journal (JBS). 2012;5(3):117-126.

Khlifa HD, Ibrahim IA, Bekhit M, Bekheet SA, El-Shabrawi HM, Szkop M, et al. Stimulation of hypericin induction in calli cultures of Hypericum sinaicum (L.). Int J Curr Res Biosci Plant Biol. 2016a;3(5):11-20.

Khlifa HD, Ibrahim IA, Bekhit M, Szkop M, Taha HS. Hypericum sinaicum L. in vitro regeneration and analysis of Hypericin content. Int $\mathrm{J}$ Curr Microbiol App Sci. 2016b;5(8):182-196.
Kitanov MK. Hypericin and pseudohypericin in some Hypericum species. Biochem Syst Ecol. 2001;29(2):171-178.

Klimek-Chodacka M, Baranski R. A protocol for sonicationassisted Agrobacterium rhizogenes-mediated transformation of haploid and diploid sugar beet (Beta vulgaris L.) explants. Acta Bioch Pol. 2014;61(1):13-17.

Komarovská H, Giovannini A, Košuth J, ellárová E. Agrobacterium rhizogenes-mediated transformation of Hypericum tomentosum L. and Hypericum tetrapterum Fries. Z Naturforsch. C. 2009;64(11-12):864-868.

Koperdakova J, Katkoveinova Z, Kosuth J, Giovannini A, Cellarova E. Morphogenetic response to plant growth regulators in transformed and untransformed $H$. perforatum clones. Acta Biol Cracoviensia Series Bot. 2009a;51(1):61-70.

Koperdakova J, Komarovska H, Kosuth J, Giovannini A, Cellarova E. Characterization of hairy root-phenotype in transgenic Hypericum perforatum L. clones. Acta Physiol Plant. 2009b;31(2):351-358.

Li L, Wang J, Lu Y, Wang Y, Zhou G, Kai G. Optimization of induction and culture conditions and tropane alkaloid production in hairy roots of Anisodusacutangulus. Biotech Bioprocess Eng. 2008;13:606-612.

Mártonfiová L, Danova K, Toteva VK, Čellárová E. Karyotype analysis of Hypericum rumeliacum Boiss. - Thaiszia. J Bot. 2014;24(2):143-150.

McInnes E, Davey MR, Mulligan BJ, Davies K, Sargent AW, Morgan AJ. Use of a disarmed Ri plasmid vector in analysis of transformed root induction. J Exp Bot. 1989;40(219): 1135-1144.

Moore L, Warren G, Strobel G. Involvement of a plasmid in the hairy root disease of plants caused by Agrobacterium rhizogenes. Plasmid. 1979;2(4):617-626.

Murashige T, Skoog F. A revised medium for rapid growth and bioassay with tobacco tissue cultures. Physiol Plant. 1962;15(3):473-497.

Nilsson O, Olsson O. Getting to the root: the role of the Agrobacterium rhizogenes rol genes in the formation of hairy roots. Physiol Plant. 1997;100(3):463-473.

Omar AK. Ecological and climatic attribute analysis for Egyptian Hypericum sinaicum. Am J Life Sci. 2014;2(6): 369-381.

Ono NN, Tain L. The multiplicity of hairy root cultures: prolific possibilities. Plant Sci. 2011;180(3):439-446. 
Agrobacterium rhizogenes-mediated transformation of Hypericum sinaicum L. for the development of hairy roots containing hypericin

Pathak M, Hamzah R. An effective method of sonicationassisted Agrobacterium-mediated transformation of chickpeas. Plant Cell Tiss Organ Cult. 2008;93(1):65-71.

Sudha CG, Sherina TV, Anand VP, Reji JV, Padmesh P, Sonia EV. Agrobacterium rhizogenes mediated transformation of the medicinal plant Decalepisarayalpathraand production of 2-hydroxy-4-methoxy benzaldehyde. Plant Cell Tiss Org Cult. 2012. Doi: 10.1007/s 11240-012-0226-6.

Trovato M, Maras B, Linhares F, Costantino P. The plant oncogene rolD encodes a functional ornithine cyclodeaminase. Proc Natl Acad Sci USA. 2001;98(23):13449-13453.

TusevskiO, Stanoeva JP, Stefova M, KungulovskiD, Pancevska NA. Hairy roots of $H$. perforatum: a promising system for xanthone production. Cent Eur J Biol. 2013;8(10):1010-1022.
Vinterhalter B, Ninković S, Cingel A, Vinterhalter D. Shoot and root culture of Hypericum perforatum L. transformed with Agrobacterium rhizogenes A4M70GUS. Biol Plantarum. 2006;50(4):767-770.

Visser RGF, Jacobsen E, Witholt B, Feenstra WJ. Efficient transformation of potato (Solanum tuberosum L.) using a binary vector in Agrobacterium rhizogenes. Theor Appl Genet. 1989;78(4):594-600.

Wölfle U, Seelinger G, Schempp CM. Topical Application of St. John's Wort (Hypericum perforatum). Planta Med. 2014;80(2-3):109-120.

Received for publication on $07^{\text {th }}$ May 2018 Accepted for publication on $14^{\text {th }}$ January 2019 